Revista Iberoamericana. Vol. LXV, Núms. 188-189, Julio-Diciembre 1999; 567-590

\title{
CANDELARIO OBESO: ENTRE LA ESPADA DEL ROMANTICISMO Y LA PARED DEL PROYECTO NACIONAL*
}

\author{
POR \\ Carlos Jáuregui \\ University of Pittsburgh
}

\author{
Para Andrés Biermann y Juan Pablo Dabove \\ Óigame, branco, tar ve \\ No é bin claro lo que aficmo, \\ A eplicácme yo no arcanzo \\ Tar como un Roja Garrío.... \\ Re toro lo grande y bello \\ Que er mundo encierra, no etimo \\ Sino ros cosa, que son \\ Mi jembra amá y mi arbedrío \\ Candelario Obeso, "Epresión re mi amitá" 26
}

UNA CASA, LA VENTANA, EL RíO

Hace poco fui a Mompox en busca de la casa en la que vivió el poeta colombiano Candelario Obeso (1849-1884). La ciudad fue el puerto más importante sobre el río Magdalena para la comunicación entre la costa y el interior durante la colonia y hasta mediados del siglo XIX, cuando el paulatino cambio del curso abrió un brazo (Loba) que dejó tras de sí al puerto con un cauce menor, inútil para la navegación a vapor que por entonces desplazaba el viejo sistema colonial de bongos y champanes (botes de poco calado).

Encontré la casa al lado del río, oculta detrás de una venta callejera del mercado que ocupa la Calle de la Albarrada. Tiene aspecto de botica abandonada, con cientos de frascos y cajas de medicinas caducas arrumadas en anaqueles y en el piso. Una placa expresa el interés de las autoridades locales por hacer un homenaje al poeta, pero hay más empeño en la restauración de la casa del marqués de aquello o del general perencejo de la guerra civil, en la que se exhiben con orgullo espadas enmohecidas y uniformes militares.

A Obeso se le metió en el Cuarto de San Alejo de la poesía colombiana adonde se entra de vez en cuando para conmemorar algún aniversario, o para pescar en el arsenal de

\footnotetext{
* Agradezco el auspicio del Center for Latin-American Studies de la University of Pittsburgh, los comentarios y sugerencias de Mabel Moraña. Asimismo quisiera señalar que este artículo es tributario en muchos aspectos de "El don de la lengua" de Julio Ramos.
} 
anécdotas insustanciales: que lo expulsaron del colegio, que se mató por una señorita bogotana de "mejor clase" que lo despreció, que al confesarse, herido de muerte por su propia mano, le explicó al sacerdote: "le apunté al blanco y le pegué al negro" (CordovezMoure 485).

La crítica ha sido en general indiferente, con la notable excepción de Candelario Obeso y la iniciación de la poesía negra en Colombia de Laurence Prescott, que salva la memoria del poeta del hambre de la polilla y de la falta de apetito del establecimiento cultural colombiano y que sigue siendo la más seria investigación sobre su obra. Salvo por este trabajo, el anterior de Richard L. Jackson, alguna nota de Nicolás Guillén, y más recientemente el artículo de Valery Wheat en el que compara la obra de Obeso con la de Paul Laurence Dunbar (1872-1906), el corpus crítico sobre Obeso ha sido escaso y anecdótico.

La suerte de Cantos populares de mi tierra, ${ }^{1}$ uno de los más originales poemarios del siglo XIX, ha corrido pareja con la de la casa junto al río, entre paredes descuidadas y bajo un techo amenazador. De vez en cuando, pese a las direcciones erráticas de los transeúntes bienintencionados, pese a estar cubierta con las baratijas del mercado y el olvido centenario, uno encuentra la casa en las mismas condiciones que la obra: en ruinas y con una placa, en ediciones descuidadas, festín de polillas.

La apariencia ruinosa de esa casa descuadernada desanima un poco; no se adivina que dentro de la obra (a mano izquierda), hay una ventana por la que el río Magdalena se cuela con una luz torrencial. Y entonces ... un milagro ocurre: imagina uno al poeta mirando desde allí el río por el que remaba su gente. Por esa ventana acaso entraba una batahola parecida a la del mercado que ahora toma la calle. Ese mundo, se piensa, ha tiempo que no existe; sin embargo el pasado, como anotaba Walter Benjamin, carga consigo un índice temporal por el que es objeto de redención, y la estructura a la que la historia está sujeta no se halla en un tiempo vacío y homogéneo sino lleno por la presencia del ahora $(254,261)$.

Hay en Cantos populares de mi tierr ${ }^{2}$ una poesía-ventana que sobrevive al tiempo, las anécdotas, el olvido, las malas ediciones y las placas conmemorativas. Allí quedaron trabadas luchas irresueltas y el juego perverso de las promesas y traiciones de un proyecto literario llamado "patria".

Este trabajo pretende examinar la posición problemática de la reivindicación literaria de la lengua vernácula de la región de Mompox en Cantos, en tanto "subversión" del proyecto literario de la nación colombiana de la segunda mitad del siglo XIX y, a la vez, gesto de pertenencia a ella.

Es preciso hacer una salvedad previa respecto al alcance de lo que llamamos subversión. Dado el papel histórico que juegan las Letras canónicas (como institución y tradición) en la generación de desigualdades y marginalidad (Beverley), es al menos

\footnotetext{
' Obeso además escribió artículos, poemas al estilo del momento, una novela (La familia Pygmalión, 1871), un memorial amoroso con prosa, poemas originales y traducciones (Lectura para ti, 1878), dramas como Don Secundino el zapatero (1880) y Lucha de la vida (1882), diversas traducciones de gramáticas y un manual de táctica militar. Para la sinopsis de estas obras ver David Peñas (en SmithCórdoba 111-132).

${ }^{2}$ En adelante me referiré a esta obra como Cantos. Las citas de este libro corresponden a la edición de 1877. Los otros textos de Obeso se citan de la de 1950, de fácil acceso aunque con erratas.
} 
discutible la afirmación según la cual esa subversión pudiera servir para construir un YO con mayúsculas, es decir, una identidad capaz de resistir el discurso hegemónico. Algunos estudios reivindican la inclusión canónica de la literatura "afro-hispánica" del siglo XIX (aún excluida pese a los golpes de pecho en favor de los textos marginales), o la celebran como espacio de lucha y "contradiscurso", sin reparar que ese tipo de lectura puede caer en la trampa de privilegiar el orden simbólico que precisamente coadyuva la producción del margen. ¿Cómo puede hablar el subalterno literariamente? El intelectual haitiano del movimiento La Ronde, Edmond Laforest, al saltar de un puente en 1915 con un Diccionario Larousse atado al cuello (Gates 13), expresaba esa contradicción, y en ella, el problema central de muchos escritores del margen étnico del siglo XIX: la raza como signo de exclusión del proyecto nacional (escriturario) y la literatura como "prueba en contrario".

El PARAíso PATRIO

Obeso vive y muere en un país fragmentado en medio de conflictos regionales que impiden la consolidación de una nación unitaria (Tirado-Mejía 21, 42). Entre 1830 y 1903 hubo en Colombia nueve guerras civiles generales, catorce guerras civiles locales, insurrecciones sin número, dos guerras internacionales, tres golpes de cuartel y la seseción de Panamá $(12,13)$. La nación surge fatigosamente bajo el fuego y violencia jurídica y lingüístico-literaria; no emerge "como resultado [...] de 'una comunidad imaginada', sino como el simple y llano resultado de la fuerza $[\ldots y$ ] del encuentro conflictivo y muchas veces caótico de distintos proyectos" (Múnera 222, 223). Para fines del siglo XIX, entre guerras civiles y sus respectivas constituciones inanes, y la "literatura nacional", se consolidaba una nación centralista y andina. ${ }^{3}$

El ente llamado Nueva Granada, Confederación Granadina, luego Estados Unidos de Colombia y al fin Colombia, se construyó como una ficción criolla entre códigos, de los que se burla Obeso, pólvora de la que reniega, y versos a cuya tradición y forma opone su experimento poético de centro dialectal. Cantos, en tanto que hace uso "disforme" de las formas lingüísticas y estéticas consubstanciales al concepto restringido y elitista de la nación, plantea una disidencia con el proyecto romántico y gramatical de la nación decimonónica.

La poesía de Obeso y la otra, la literatura nacional, pomposa, romántica o de exaltación costumbrista de lo criollo, contrastan (estando ambas dentro del círculo letrado); su contrapunto sirve aquí para resaltar la falacia de la armonía fundacional de la nación, una ficción que no se compadece de la inmensa heterogeneidad de Colombia, ni de los procesos jurídicos y literarios de exclusión de las diferencias, ni de los conflictos entre facciones y élites regionales, o entre éstas y sectores marginados y populares, todo lo cual queda diluido en el discurso de la armonía mítica aglutinante con que José María Cordovez-Moure refiere la manumisión de los esclavos: ${ }^{4}$

\footnotetext{
${ }^{3}$ Me refiero al proyecto de la élite andina impuesto desde Bogotá y que paulatinamente derrotó los proyectos de las élites de otras ciudades como Popayán y Cartagena (Múnera).

${ }^{4}$ Durante el gobierno de José Hilario López se expidió la ley del 21 de mayo de 1851 que otorgó la libertad a los esclavos desde el 1 de enero del año siguiente.
} 
El 1 de enero de 1852 se engalanó la República con el pabellón nacional, izado en todas las poblaciones para que a su sombra se agrupasen sus hijos en fraternal abrazo, puesto que ya no existían las odiosas distinciones de amo y siervo; los esclavos de la víspera se presentaron cubiertos con el gorro frigio de la libertad que los hizo ciudadanos de un país libre (Cordovez-Moure 475).

El olvido - como decía Ernest Renan en 1882- es un factor crucial en la creación de la nación (11); Cordovez-Moure omite mencionar las insurrecciones y resistencia de los esclavos, la guerra impulsada desde los estados esclavistas que siguió a la manumisión y los mecanismos intermedios entre la esclavitud y el trabajo asalariado que perpetuaron la servidumbre (Tirado-Mejía 15, 99-112; y Tirado-Mejía en Jaramillo 368).

El resultado de esta serie de omisiones es el discurso nacional del "abrazo fraterno" en el cual "los esclavos de la víspera se presentaron cubiertos con el gorro frigio de la libertad."

En una charla sobre Obeso, Ramiro Lagos reproducía sin rubor, en 1982 (!), ese tipo de retahíla nacionalista:

Colombia fue crisol de un claro mestizaje acriollado, donde la raza se funda no en el color sino en el bronce de su valor y de su épica, [...] es quizá una de las naciones que más se han liberado, por su cultura, de las consabidas discriminaciones que separan al blanco del negro, del mulato, del aindiado [...] considerándose Colombia uno de los paises más hispánicos, no sólo por la sangre cultural que colma su espíritu neorenacentista [!], sino por el purismo de su lenguaje castizo con el que se expresan, para hablar con énfasis y claridad, las voces múltiples de sus portavoces raciales. La cultura criolla definidora de la unidad y la idiosincrasia colombiana allana todo complejo racial proporcionando escalas de superioridad a quien por los caminos del arte llega a subir como epónimo (217, énfasis mío).

Estas líneas de exaltado tono patriótico son buen ejemplo de la retórica que desde el siglo XIX repite el discurso oficial de "la esencia criolla" con los lugares comunes del "valor de bronce", "el hispanismo", la pureza del lenguaje "castizo" y la propuesta implícita de que una supuesta paz racial significa la democrática "ausencia de racismo". Lo primero, la "paz racial", es un presupuesto no sólo falso sino irrelevante, es decir que, aún aceptándose, no podría derivarse de él la consecuencia de una Colombia en la que "no existe puerta trasera para razas discriminadas" (217). Esa es la ficción escolar del paraíso patrio que, para ponderar sus virtudes democráticas, resalta el caso excepcional, cuando por el contrario, lo que las excepciones comprueban es la regla general contraria: el tropo "raza" funciona distribuyendo diferencias (lenguaje, cultura, moral, color de la piel) en una economía de privilegios arbitraria (Hall). El segundo presupuesto es la base hispánica de la nación que generosa promete la integración de las narrativas de grupos marginales a la gran narrativa nacional. Pero en Colombia la celebración de la hispanidad, a la que los propios mestizos se sumaron jubilosos, ha encumbrado el mestizaje como "solución" para las contradicciones sociales y ha sido coartada de "lo civilizado" frente a la "barbarie" del cambalache étnico. Obeso mismo por momentos hizo eco de esa retórica: 
Solo una cosa le piro,

[...]

Le cuente a toito er mundo

Lo que aquí en Colombia ha vito;

Riga como ciuraranos

Son er negro, er branco, er indio ("Epresión re mi amitá" 27).

Ya pasó er tiempo

Re loj esclavos;

Somo hoi tan libre

Como lo branco ("Serenata" 30).

\section{LA CIVILIZACIÓN CONTRA EL CURRULAO}

Alexander von Humboldt, que con una mezcla ambivalente de distancia y admiración, caracterizó tempranamente a los bogas, es decir, a los remeros negros o zambos ${ }^{5}$ del río Magdalena, decía:

van desnudos a excepción del guayuco; de fuerza hercúlea [...] avanzan poderosamente apoyados en la palanca [...] se les hincha cada vez la vena yugular, [...] chorrean sudor diariamente durante trece horas [...S] on hombres libres [...] muy altivos, indómitos y alegres [...] Pero lo más enojoso es la bárbara, lujuriosa, ululante y rabiosa gritería, a veces lastimera, a veces jubilosa; [...] Para aspirar más aire en los pulmones es también necesario expeler más aire viciado. Por eso en el trabajo pesado son muy naturales los quejidos y la emisión de sonidos. Si el trabajo (esfuerzo), tiene cierta cadencia regular [...] se añade un factor psicológico. El placer por la cadencia hace que los tonos sean expresados en una forma más determinada, Hau, Hau. . . . . Ham, Ham. .... . Halle, Halle. Si se agrega todo lo imaginable, el articulado tono se convierte en canto, y aún en diálogo [...] El estruendo se oye ininterrumpidamente durante 35 días. (148)

Durante la vida de Obeso el río empezó a morir. En un poema dedicado al "majestuoso río" de las "dulces horas de la niñéz" decía:

¡También en ti la muerte despiadada

Hondos estragos hizo!

Tal como en ti, sobre mi noble patria,

Sobre mi pobre hogar ya oscurecido,

Se cebó el infortunio. Estás desierto,

Nosotros abatidos.

El caudal de tus aguas, ya copioso,

Tan ancho, tan profundo, empobrecido

Entre abrojos se arrastra. Sólo penas

Marcan nuestro camino

(Citado por Luis Toscano en Smith-Córdoba 134-5).

\footnotetext{
${ }^{5}$ Aunque las relaciones entre negros e indios fueron prohibidas por la Corona española, el zambaje -la mezcla del negro con la india- se convirtió en el "patrón racial" del Magdalena (Peñas 9).
} 
La navegación comercial a vapor por el Magdalena inició la deforestación de las riberas y la extinción del "Champán" y del boga, hasta entonces imprescindibles para la comunicación y articulación entre la capital y la costa. La ideología de la civilización y el progreso empezaba a cambiarle la cara al territorio topando a su paso con cierta resistencia:

Como los gitanos de Europa, los bogas no aprenden ni olvidan nada, son siempre los mismos. No se dan por notificados del movimiento social [...] Lo único que los ha indignado un poco es la venida de los vapores, a los cuales han hecho una oposición apasionada y sistemática (Kastos —Juan de Dios Restrepo- 520, énfasis mío).

La poesía de Obeso es de alguna manera reparación simbólica de un universo cultural fracturado y canto al margen telúrico, lo cual se manifiesta no sólo en la defensa de valores tradicionales, sino en el partido que, en el conflicto entre civilización y barbarie, toma contra la ciudad:

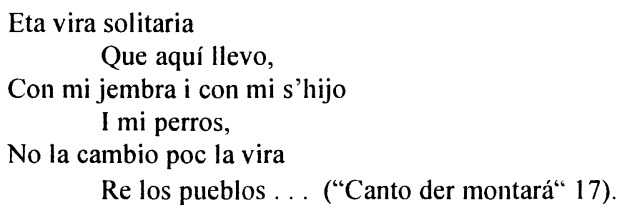

Pero no se trata de una celebración bucólica, ni del paisajismo común en la literatura romántica terrateniente colombiana, sino de una reivindicación del campo como espacio poético fuera del alcance del Estado. Por ese motivo el montarás celebra la lejanía del gobierno:

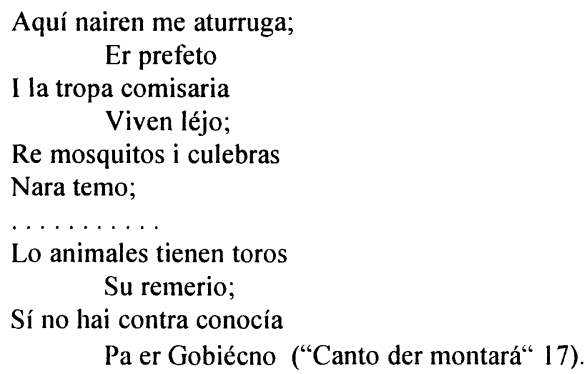

Entre estos personajes poéticos disonantes y resistentes al "progreso" como el montarás, sobresale el boga, cuyo canto, en la poesía de Obeso, no es ciertamente alegre sino nostálgico o funeral de un mundo en el que irrumpe el progreso y al cual el Estado extiende su campo de acción. La atmósfera y las escenas predominantes de sus poemas son previas a la modernización, como el solitario nauta del río que se refugia en el ritmo de los dos golpes de remo ("Remá, Remá", "Bogá, bogá") mientras piensa en la amada o en su rancho. La única acción es la de remar. Lo demás es nostalgia: 
Que trite que etá la noche,

La noche que trite etá

No hai en er Cielo una etrella. . . .

Remá, remá.

[...]

Que ejcura que etá la noche;

La noche que ejcura etá;

Asina ejcura é la ausencia. ...

Bogá, bogá ("Canción der boga ausente 15).

Bogá, Fracisco, bogá;

I no orvire que la vira

Son pesare i nara maj;

Que la richa é puro jumo

Tú lo sabe poc remaj!. . ("A mi morena" 35).

La modernización no constituía una opción sino una fatalidad del orden económico internacional, coadyuvada internamente desde un sector mayoritario de los cuadros dirigentes criollos y los partidos tradicionales. Las diferencias de éstos en cuanto a mantener un sistema oligárquico de raigambre hispánica o imponer la propuesta de modernización que el capitalismo en expansión requería dentro del pacto neocolonial, son cada vez menos acentuadas. Aunque algunos sectores conservadores se apegaban al idilio colonial —algo especialmente visible en los cuadros de costumbres y la literatura romántica terratenientea medida que avanza la segunda mitad del siglo XIX la oposición a la modernización es cada vez más flaca.

Los discursos coinciden adicionalmente en el principio excluyente que el proyecto del progreso supone, y en los sujetos pasivos de esa exclusión: negros, campesinos, analfabetas, mujeres, indígenas, no propietarios...

Ningunas palabras como las de José María Samper (1831-1888) —ejemplo del Romanticismo criollo - revelan mejor la máscara del liberalismo colombiano, detrás de la cual están los mismos prejuicios y privilegios enarbolados por el conservatismo y que fueran el substrato ideológico de la "Regeneración" conservadora y la constitución de 1886 (dos años posterior a la muerte de Obeso).

Samper participó junto con otros hombres de letras, bajo la influencia de Rafael Núñez (1825-1894) y Miguel Antonio Caro (1843-1909), en el equipo de redacción de este documento que sella la imposición jurídica de la nación unitaria (consolidada con la derrota militar del liberalismo radical) y que contiene el programa político de la oligarquía centralista contra los intereses locales y de la burguesía fabril que había apoyado la constitución radical federalista de "Rionegro" en 1863.

La formación liberal de Samper - quien pertenece al sector más tolerante- no es óbice para las menos democráticas observaciones sobre el país de los márgenes del río Magdalena, opuesto al de sus sueños de civilización:

Allá el hombre primitivo, tosco, brutal, indolente, semi-salvaje y retostado por el sol tropical, es decir el boga colombiano, con su insolencia, su fanatismo estúpido, su cobarde petulancia, su indolencia increible y su cinismo de lenguaje [...]; y más acá el europeo, 
activo, inteligente, blanco y elegante, muchas veces rubio, con su mirada penetrante y poética, su lenguaje vibrante y rápido, su elevación de espiritu, sus formas siempre distinguidas (88, énfasis mío).

Para él, la distorsión del lenguaje es prueba intolerable de inferioridad racial y una nota disonante e insolente, en el concierto civilizado de su república utópica. Pretende que la diferencia se nombre a sí misma. El boga-dice—no entiende religión ni ley, la civilización es en su mente "una niebla espesa" (88), y agrega: "descendiente de Africa, e hijo del cruzamiento de razas envilecidas [...] no es más que un bruto que habla un malísimo lenguaje, siempre impúdico, carnal, insolente, ladrón y cobarde” (94, énfasis mío).

Después de haber cantado La Marseillaise y God Save the Queen, con los pasajeros nacionales y extranjeros del barco en que viajaba (!), Samper tuvo la oportunidad de escuchar y ver en tierra un currulao. El escándalo del jurista y escritor es mayúsculo. Alrededor de la "luz rojiza de la hoguera" ve al demonio en cada uno de los pasos de ese baile y escribe contra él líneas antológicas:

El currulao es la danza típica que resume al boga y su familia, que revela toda la energía brutal del negro y el zambo de las costas septentrionales de la Nueva Granada [...] con una voluptuosidad, de una lubricidad cínica, cuya descripción ni quiero ni debo hacer [...] no se ve en toda la escena sino el instinto maquinal de la carne, el poder del hábito dominado por la materia [...] La civilización no reinará en esas comarcas sino el dia que haya desaparecido el currulao, que es la horrible síntesis de la barbarie actual (93-94, énfasis mío).

El currulao "resume" y "revela" la lubricidad y voluptuosidad corporal de la oralidad. La civilización (asociada siempre al proceso modernizador) como el barco de pasajeros con sus máquinas de vapor- transita la barbarie en la que reina el "instinto maquinal de la carne". Entre himnos foráneos ese barco subscribe la extranjería de la ideología del progreso, para cuyo reino anunciado debía desaparecer el currulao y ser domeñada la oralidad voluptuosa por la disciplina de la letra.

Por la arteria fluvial del Magdalena subían las mercaderías y muebles con que los criollos de "casta" llenaban su casas, y los pianos con los que se empezaba a tocar música europea (Cané 193). Obeso venía de una tierra de tambores y gaitas, a cantarle al boga, ícono de la barbarie.

El viaje de Obeso desde Mompox en 1866 (Añez 18) es doble: la jornada por el río Magdalena hasta Honda y luego a pie hasta la capital (ver "Sotto voce" en Obeso 1950, 37), y también el viaje del margen al centro donde la patria se escribía: "la Atenas suramericana", como aún se le llama a Bogotá con ocasión de "lo castizo de la lengua", la "corrección" de la dicción y la "vocación ilustrada" de los gobernantes poetas y tribunos.

Entre el mar y esa "Atenas" había una tierra salvaje de gente desnuda y vocinglera que hacía "terribles imprecaciones a mandinga" (Cordovez-Moure 481), y que era amiga del demonio:

Tenían aquellos nautas su forma de hablar muy peculiar y su jerga de navegación especial, que mezclaban con imprecaciones a las almas del purgatorio, a los santos católicos, a 
mandinga o diablo y las cuales subrayaban con fluidez de groserías y obscenidades (Triana y Antorveza 280).

Era un mundo en grave y alevosa ruptura sintáctica y en falta con la "gramática" de la nación. La oralidad del campesino montaraz o del boga es desautorizada incluso cuando, como en el caso de Obeso, está revestida bajo el ropaje "amable" de la letra.

Ritos festivos como el currulao tenían mejor suerte en la producción de significados de cohesión social y creación de identidades de esos grupos al margen que el rito "grecolatino" que se practicaba en Bogotá. No obstante, en el proyecto nacional los sujetos sin Literatura no participaban en la producción de significados sociales con centro en la polis y, fuera del discurso, no podían reconocerse ni ser reconocidos como ciudadanos de la "Atenas letrada". El desorden de lo oral y el color (en el sentido racial y poético) que Obeso pretendía introducir en su versión literaria de este mundo ágrafo, eran máculas disonantes para la "gloria inmarcesible" y "jubilo inmortal" de la ciudad letrada, esa versión indica los límites de la ciudadanía. No bastaba la literatura para pertenecer a la nación, era necesario que esa literatura se plegara a lo hispánico, que pretendiera una genealogía latina y castiza, que no entrara en relaciones promiscuas con la oralidad y abjurara, en fin, del currulao, el "Ham, Ham", y la "bárbara, lujuriosa, ululante y rabiosa gritería" (Humboldt 148).

\section{LA ALDEA ATENIENSE}

La vida de Obeso ocurre en un país analfabeto y rural, al tiempo que marcado y regido gramaticalmente. Se piensa en la Bogotá de Obeso como la "Atenas suramericana" por "ser centro activo y renombrado del cultivo de las artes y las letras, de la impresión de libros, de las tertulias literarias" (Prescott 54). Detengámonos en esa aldea gris con la presunción de hablar el más perfecto español, a la que él llega a estudiar en el año 1866, de la que parte a la guerra en 1876, a una misión diplomática en $1881,{ }^{7}$ en comisión militar a Panamá en 1884, y a la que regresó a morir en abril del mismo año (Prescott 61-71).

La historia de la villa culta en los Andes debe ser matizada con otra Bogotá de la que dieron cuenta varios viajeros, una ciudad racista, sin negros, ${ }^{8}$ que rendía culto a la gramática y en la que Obeso fuera posiblemente el único escritor de color."

\footnotetext{
"Versos del "Himno nacional" compuesto por el "poeta" y presidente "regenerador" Rafael Núñez (1825-1894).

${ }^{7}$ Fue nombrado Cónsul (más o menos honorario) en Tours, Francia, durante el gobierno de Núñez. Su estadía es corta debido a los apremios económicos que el gobierno no alivia (Prescott 68).

${ }^{8}$ Acojo diversos relatos de viajeros, en particular el que hace Rosa Carnegie-Williams de su estadía entre 1881 y 1882 ; en la entrada de su diario de enero 31 dice: "Me sorprendió ver pasar a una negra, un tipo no usual en Bogotá, cuyos habitantes son generalmente bien parecidos" (92).

"Alfred Hettner, en la memoria de sus viajes entre 1882 y 1884, hace un cálculo por extensión de área habitada con un resultado de entre 50 y 60 mil habitantes (213), divididos socialmente por clases que dependen de la raza: "Esta composición de las clases por razas hoy no tiene base legal alguna, atribuyéndose su origen a una herencia conservada desde la colonia [...] Los descendientes de raza blanca se ufanan de su linaje español, especialmente de su trato con europeos" (214). Calculó que más
} 
Al médico y botánico francés Charles Saffray, que visitó Bogotá en la década de 1860 , le llamó la atención el orgullo desproporcionado de los bogotanos por su ciudad y que la primera y casi única industria fuera la de poetas, tan prolífica como pésimo era el sistema de educación de esa "Nueva Atenas" (166-169).

El escritor argentino Miguel Cané hace un cuadro de la Bogotá de 1882, una ciudad con las costumbres de la España de Cervantes y calles llenas de basura y gallinazos (178), y anota las dificultades que él, un diplomático, pasara en una comida social siguiendo la etiqueta (187). El relato del geógrafo Alfred Hettner lo secunda: "resulta en forma hasta repugnante observar a los bogotanos sometiéndose a toda clase de cumplidos exigidos por la etiqueta europea, solamente por considerar ésta como parte de la civilización" (222). ¡Cuánto sufriría Obeso entre las ceremonias que la clase alta realizaba para distinguirse de la gleba a la que él, por su "color", pertenecía!"

En cuanto conjuntos normativos y ritos de reconocimiento y exclusión es equivocado imaginar cortes radicales entre ley, reglas de urbanidad, gramática y Literatura. "Cada una en su especie [...] son discursos fundacionales de fronteras. Su propio lenguaje está forjado a partir de la prohibición. Una cadena de compuertas que permiten y prohiben el ser o no ciudadano" (González 34).

Esa ciudadanía se fragua no sólo en la etiqueta, o en el universo jurídico o literariogramatical. El paisaje urbano también es significante de las fronteras de la nación; fronteras monumentales reñidas con la realidad, como pasa con el plan absurdo y monstruoso del Capitolio, un edificio a medio terminar descrito por Cané:

Fue empezado hace diez años, ha tragado cerca de un millón de pesos fuertes y no sólo no está concluido, sino que creo que no se concluirá jamás [...] A la entrada [...] una docena de enormes columnas que concluyen truncas[...] en el vacío. No sostienen nada, no tienen la misión de sostener nada, no sostendrán jamás nada (184, énfasis mío).

El quehacer intelectual en Bogotá y el proyecto nacional criollo eran románticos en la versión conservadora de un romanticismo singular que abrazaba el mito del progreso, se jactaba de una tradición occidental clásica, cuyo epítome eran las columnas de ese capitolio, levantadas sobre una nostalgia ajena y falsa para sostener el aire, el vacío de un diseño arquitectónica y literariamente ostentoso: la nación.

Otra de las particularidades "griegas" de la capital comentadas por Cané es el Altozano o atrio de la Catedral en la Plaza de Bolívar. El Altozano era una "bolsa, un círculo literario, un areópago, una coterie [...], una coulisse de teatro, un forum, toda la actividad de Bogotá en un centenar de metros cuadrados" en donde se daban cita los ciudadanos de la elite, "la créme de la créme según la expresión vienesa que han adoptado" $(186,187)$; un espacio citadino excluyente, criollo y masculino para chismorrear, discutir de la vida social y política, decidir guerras fratricidas, escalar posiciones políticas y hacer negocios.

\footnotetext{
o menos un $15 \%$ de la población era blanca con algunos rasgos mestizos, un $1 \%$ negra y zamba. De ser esto correcto, Obeso sería uno de los quinientos negros de Bogotá en 1882 y tal vez el único letrado. ${ }^{10}$ En poemas como "Lucha y conquista" $y$ "Parábola" es patente "el agudo choque cultural del costeño trasplantado al altiplano" (Peñas 97).
} 
Bogotá era una ciudad irreal entre calles llenas de excrementos, aves carroñeras, indígenas descalzos, mestizos de ruana y una aristocracia entre la que sobresalía el tipo de "joven elegante recién llegado de París con un amplio surtido de vestidos de última moda, con botines de charol, [y] con su monóculo puesto" (Hettner 205, 209, 211), una ciudad cuya plaza estaba adornada en el extremo sur con las columnas y capiteles de un edificio "al estilo griego casi puro" (207) en ruinas antes de su construcción y en el oriente con una iglesia en cuyo atrio se definía la honra ajena y se planeaba la guerra de turno; una ciudad entre acordes de Chopin y una epidemia de elefantiasis (Cané 182); una ciudad sin librerías (Hettner 246) en la que se traducía a Virgilio a puerta cerrada y los miembros de la élite se declamaban entre sí versos rimbombantes (Jaramillo-Zuluaga 473). Una ciudad en fin, donde el delirio grecolatino alcanzaba los nombres de la gente "derivados [...] de personajes notables griegos o romanos [...] Don Milcíades, Don Arístides, Don César, etc.” (Hettner 215).

Para dar idea de la persistencia desde el siglo XIX de este imaginario entre la clase dirigente, baste señalar que hacia mitad de este siglo un grupúsculo de hombres públicos de letras de la zona cafetera de Caldas, tan reaccionario y provinciano como poderoso, se conoció como "greco-caldense", en un gesto que nomina la ridiculez, pero también la arrogancia estentórea de estos referentes simbólicos de la nación.

Las observaciones finales del relato de Cané aclaran qué se entendía por Colombia en su capital y qué sector escribió la nación: "Colombia se ha refugiado en las alturas, huyendo de la penosa vida de las costas" (197, énfasis mío). La salvaje realidad que debajo de la Atenas se extendía hasta el mar y de donde venía Obeso caminando en 1866, no era Colombia sino aquello de lo que Colombia se refugiaba "en las alturas".

\section{El Romanticismo, LA gRamática y LaS PROMESAS ROtaS de LA NACIÓN}

Atendiendo a cierta temática más o menos constante, a Obeso se le clasifica dentro del Romanticismo literario colombiano que se cultiva hasta finales del siglo XIX. " La propia vida del bardo, azarosa y errabunda, y su final de suicida de leyenda, indican una filiación werteriana; el inventario temático de Cantos es en este sentido típico: patria, familia, naturaleza, la amada, el amor imposible, presentación positiva del rebelde, ${ }^{12}$ apuesta por el campo contra la ciudad, y exaltación de una libertad idílica:

Amo yo la libectá

Como er pájaro a su nío;

Como la flore a la lluvia,

Como ar agua er bocachico (“Epresión de mi amitá 27).

El Romanticismo colombiano por su casticismo, postura política, misoginia, adscripción católica e indiferencia a las aventuras formales, puede en general calificarse de conservador.

\footnotetext{
"Algunos de cuyos exponentes son José Eusebio Caro (1817-1853), Julio Arboleda (1818-1962), Rafael Núñez (1825-1894), Gregorio Gutiérrez González (1826-1872), Diego Fallon (1834-1905), Rafael Pombo (1833-1912), Jorge Isaacs (1838-1895), Epifanio Mejía (1838-1913) y Julio Flores (1867-1923).

12 "Er boga chaclatán" (18-20) es un canto al héroe prófugo que es capaz, por mañas de su magia, de burlar a las autoridades, cambiar el color de sus ojos y hablar muchas lenguas (como el propio Obeso).
} 
Si bien Cantos no escapa y participa de varios aspectos de este conservadurismo, se trata de una voz deliberadamente descentrada, inclasificable y rara dentro del perímetro de la ciudad letrada romántica, en la que Obeso intenta insertarse y que simultáneamente trata de subvertir.

Es importante destacar que la singularidad de Cantos no proviene del "color"l3 $\mathrm{de}$ Obeso, sino del color de la lengua usada y de su alejamiento del proyecto nacional. El poema "Epropiación re uno córigos" es, entre otros, un buen ejemplo de la doble distancia (formal e ideológica) de Cantos del Romanticismo colombiano:

1. La norma general del libro es la desautorización del culto castizo a la lengua mediante el énfasis en un centro lingüistico dialectal. Con clara conciencia del desencuentro cultural que el experimento formal propiciaba, el poema "Epropiación re uno córigos" es "traducido" por el propio poeta en una "Versión castiza" en prosa $(24,25)$. A diferencia de las obras románticas en las que la "barbarie lingüística" es una cita del Otro, "Epropiación re uno córigos" dramatiza la propia heterogeneidad del letrado marginal. La traducción es un guiño que indica su habilidad para habitar literariamente mundos diversos y también un reconocimiento de los límites de la autoridad textual del dialecto al tratar de insertarse en un sistema de producción cultural letrado.

2. Por otro lado, el poema se refiere a otros textos - en este caso jurídicos- pero no como intertextos de los que se sirva para autorizarse sino como pretextos de la desautorización del culto a la ley. En efecto, la voz poética se disculpa ante su interlocutor por haber empeñado unos códigos que tenía el encargo de llevarle y que vendió para comprar almidón y reparar su choza (se sirve de los códigos contra la ley que éstos contienen). A guisa de disculpa ofrece reponer el papel si - dice- "uté papé necesita" (22), sometiendo los códigos a una materialidad y lógica que los convierte en objetos sin más valor que el del papel que los soporta.

El lugar de Cantos, que permite la doble distancia de la que hablamos, está en el punto de cruce de dos coordenadas: una que sigue la trayectoria romántica y del proyecto nacional entre sus códigos, versos y edificios inverosímiles, y otra popular, fundada en la "tradición oral". En esta intersección está la poesía de Obeso revestida de los apretados moldes escriturarios, y a la vez des-hormando la matriz estética de la literatura romántica a fuer del lenguaje. El capital lingüístico intencionalmente deficitario de Cantos es paradójicamente excesivo tanto para las formas románticas, como para el proyecto oligárquico nacional.

Esa ubicación problemática o heterogénea hace que a un mismo tiempo Cantos funde su autoridad textual en un gesto contra el casticismo ritual del Estado de gramáticos, y que sea a ellos con nombre propio, que esté dedicado: José María Samper, Miguel A. Caro y Rufino José Cuervo ${ }^{14}(3)$, entre otros.

\footnotetext{
${ }^{13}$ Wheat (26), como Jackson (Black Writers 53-62), ve en el uso del dialecto un "statement of black pride". El problema no es tan simple por varias razones: 1. La preeminencia del zambaje en la región (Peñas; Fals Borda); 2. Obeso se definía mulato (Prescott, Afro-Hispanic Review 8/14); y 3. La subversión lingüística emerge del uso axial del dialecto de "su gente", es decir, el asunto racial no se puede escindir de lo cultural, regional y popular.

${ }^{14}$ Obeso dedica además doce de los dieciséis poemas a varios letrados, por ejemplo "Lo palomos" a Rafael Pombo, el poeta romántico nacional y "Canción der boga ausente" —poema emblemático
} 
Malcom Deas en un ensayo-viñeta resalta, entre estupefacto y divertido, la "obsesión nacional filológica-gramatical [...] íntimamente conectada en Colombia al ejercicio del poder" (26). Recuerda, citando a Benedict Anderson, que el siglo XIX "fue la edad de oro de los lexicógrafos, gramáticos, filólogos y letrados vernaculizantes" y que "su rol en el surgimiento de muchos nacionalismos es bastante familiar" en un proceso o "fenómeno típicamente colonial, el de pueblos todavía inseguros [...] que trataban de reafirmarse demostrando que eran aún más correctos que la madre patria" (27).

Para los letrados, para los burócratas, el idioma, el idioma correcto, es parte significativa del gobierno [...] para ellos lenguaje y poder deberían permanecer inseparables [...] la lengua permitía la conexión con el pasado español, lo que definía la clase de República que estos humanistas querían (Deas 42, 47).

Los hombres de letras colombianos del Estado del siglo XIX tienen entre sus designios empresas increíbles como un tratado de ortografía en verso ("con zeta se escribe, azada, vergüenza, / azar, despanzurra, bizcocho, azafrán, / azufre, bizarro, calzones y trenza, / coraza, lechuza, durazno y azacán") de José Manuel Marroquín (1827-1908) quien perdiera Panamá siendo presidente, o el sin parangón Diccionario de construcción y régimen de la lengua castellana, iniciado por Rufino José Cuervo (1844-1911) quien autoexiliado en París - lejos de la lengua sobre la que escribía - dedicó a este esfuerzo vida y fortuna, y llegó hasta la letra $D$. Cien años después lo terminarían los gramáticos colombianos y lo lanzarían en España con discurso del rey, para acentuar la genealogía de la nación imaginada.

El discurso gramatical forja la diferencia y frente a ella se constituye como fuerza disciplinadora de la oralidad y su caos:

La palabra dialectal es irregular y monstruosa [...] pero es lo que, al mismo tiempo, define la diferencia [...] Tal es precisamente la aporía irreductible y constitutiva del discurso gramatical que funda su legitimidad en nombre de la diferencia, y con el mismo movimiento intenta categorizar la particularidad de su objeto, sometiéndolo al discurso generalizador de la nación (Ramos 20).

En este sentido la Gramática de Nebrija (1515) en un imperio naciente y el diccionario de Cuervo en una república en ciernes y amenazada por el federalismo de las regiones, se hermanan. Ambas obras oponen al desorden, el orden normativo del lenguaje. En 1872, respondiendo a la misma preocupación, se crea en Bogotá la primera academia americana de la lengua cuya finalidad declarada era la de evitar la fragmentación del idioma.

Detrás de esa pirotecnia jurídico-literaria (constituciones, gramáticas, literatura romántica) hay un discurso fundacional cuya oquedad no es gratuita y que valía por las galas de su forma. Hettner en 1882 calificaba el lenguaje público con el que se hablaba o discutía de política en Bogotá como un "diluvio de frases resonantes pero vacías [...] dominadas por el mayor formalismo, el más rígido doctrinarismo, dejando entre líneas los problemas reales, aún los más apremiantes" (255).

del libro- a Caro y Cuervo, cabezas visibles de la república de gramáticos de formación latina y purismo castellano. 
Esta misma vacuidad puede imputarse a la poesía cuyo medio principal de difusión no fue el libro sino la recitación en salones sociales (Jaramillo-Zuluaga 471-483), lo cual antes que privilegiar la oralidad (de la elite) la sujetaba a la perfección sintáctica y gramatical. La práctica recitatoria es regida por las reglas del arte de citar y re-citar la letra. La gran mayoría de esta poesía está hecha de versos vacíos pero significantes de la diferencia, y sobre todo sonoros, como corresponde a una literatura que acalla los gritos y el "ham ham" del currulao. Cantos, no lo olvidemos, excedía las posibilidades declamatorias, y aún hoy resulta dificil de recitar.

El discurso republicano, liberal o conservador, jurídico, literario, laudatorio de la historia patria o de las costumbres criollas, tenía como requisitos sine qua non la escritura - divisa de autoridad - y la corrección gramatical, quizás porque en la perfección de las formas, había un significado per se: allí se excluía lo ágrafo, y se sentaba la minoría de edad de grupos, fuera de la "nación hispánica" como los negros y los indios. Ese culto letrado o gramática del poder, contiene la propuesta ínsita de la incorrecta redacción de narrativas diversas y la pobreza sacramental de la oralidad, asociada por Cané al cuerpo.

La poesía popular no tuvo por largo tiempo el soporte tecnológico de la imprenta o de la escritura pues se fundaba ( $y$ aún se funda) en la tradición oral, la memoria y la performance del canto. En el substrato de leyendas y canciones y en la música de ciertas zonas como el Pacífico colombiano y el Magdalena, existen imaginarios y estéticas con una larga genealogía en esa tradición como el propio poeta lo reconocía con la transcripción de una canción de la costa en su "Advertencia del autor" $(7,8)$.

La variedad de la población africana "importada", y su procedencia lingüística diversa facilitaron la adopción del español como lengua matriz, en la que confluyeron matices léxico-sintácticos, sistemas axiológicos y estéticas diversas y extrañas a los gustos de las élites.

La lengua pública del aparato estatal, ceremonial y escrita, es opuesta al "desorden", a la lengua popular escasamente registrada, como no sea para censurarla.

El Romanticismo había tematizado al negro y/o imitado su voz en contraste con el español castizo. Obras, canónicas como El matadero (1838-40, publicado en 1871), María (1867) o Martín Fierro $(1872,1879)$, por ejemplo, tiñeron el lenguaje o la trama con visiones idílicas o bestiales del "Otro" (negro, indio, zambo, mulato) como antes lo habían hecho Francisco Quevedo, Andrés de Claramonte, Sor Juana Inés de la Cruz, Juan del Valle y Caviedes y lo harían después Rubén Darío y los negristas de las Vanguardias. El centro lingüístico de los textos no se desplazó del eje culto, sino que coloreó la trama y el lenguaje hegemónico con el habla popular. Varias crónicas y cuadros de costumbres intentan este "toque curioso" del lenguaje de los Otros. Así, el empleo literario del habla del Magdalena en Manuel Madiedo con el cuadro "El boga del Magdalena" (1850) (511-513), y su novela José de la Crú Rodrigue, boga de corazó (1857) (Triana y Antorveza, 281), o los experimentos de representación del habla de los negros esclavos en Maria (1867) de Jorge Isaacs.

La escritura del dialecto en esas obras circunscribe disciplinariamente la oralidad, y lo sitúa dentro de un espacio de barbarie; es una cita de la otredad monstruosa. Por el contrario en Cantos el dialecto se escribe como centro. Una cosa es el motivo costumbrista del Romanticismo criollo y otra la irrupción de una obra con centro dialectal. Obeso escoge 
como materia prima de "lo literario" aquello respecto y en contraste con lo cual "lo literario" decimonónico se define. He ahí su originalidad y también el origen de lo que podríamos llamar el fracaso de la "subversión de "lo literario"" desde la Literatura.

Lo que fuera alabado en Isaacs, no lo fue en Obeso. Hoy todavía se escuchan voces de queja por el experimento de representación fonética que intentó. Dice José Socarrás en un cuestionable artículo acompañado de una superficial diagnosis psiquiátrica del poeta:

Para mí tengo que el momposino ha permanecido en la penumbrapor el uso de tal dialecto. Esa es la razón de que yo haya citado los versos transcritos en grafía general [...] Leído en castellano sin arandelas, se advierte al momento que hubo comunidad de inspiración entre Obeso y José Martí (255, énfasis mío ).

Esta arrogancia que llega al delirio de la corrección del texto opuesta al poema y a la dicción que es condición de su métrica musical y rima, encierra un claro desprecio por las "arandelas" del "dialecto", definido como deficiente en relación con el lenguaje con el que la ficción nacional se construyó. El caso es extremo, pero significativo. La grosera deformidad de Cantos no le da color a un cuadro de costumbres, ni es un coro de negros que "canta" en un villancico del Barroco, en las estancias de la servidumbre de una hacienda de una novela romántica o en la recopilación de "literatura oral" hecha por un folklorista o antropólogo. Todos esos discursos construyen un espacio en el que lo diferente tiene su lugar.

En “Advertencia del autor" de Cantos, Obeso explica el sistema de representación fonológica de los poemas y hace unas breves observaciones entre las cuales resalta su insistencia en una literatura nacional de substrato popular:

[...] en la poesía popular hai i hubo siempre, sin las ventajas filolójicas, una sobra copiosa de delicado sentimiento, i de mucha e inapreciable joya de imágenes bellísimas. Así, tengo para mí que es sólo cultivándola con el esmero requerido como alcanzan las Naciones a fundar su verdadera positiva literatura. Tal lo comprueba el conocimiento de la Historia. Ojalá, pues, que de hoi más, trabajen este propósito [...] los jóvenes amantes del progreso del país, i de esta suerte pronto se calmará el furor de imitación, tan triste, que tanto ha retrasado el ensanche de las letras hispanoamericanas (8).

Cantos, en contraste con el Romanticismo imitativo y culto, busca una posición estética ajena al folklorismo costumbrista que imposta una voz desde el discurso "civilizado". Su deformidad proviene de pretender ser Literatura. Obeso intenta incluirse en la ciudad letrada con un registro popular y reclama la autoridad de esa poesía que llama nacional. Desde un eje descentrado arroja una bomba poética en el interior de un círculo que creía ser parte del mundo occidental europeo y obliga a mirar la "otredad" en la literatura colombiana.

Ahora bien, Obeso, que declara representar narrativas marginadas("cantos populares"), no es sin embargo un poeta "silvestre"; maneja cómodamente la lengua castiza, su gramática y retórica, puede escribir dramas y poemas que siguen los modelos románticos, e incluso traduce Otello (trad. en 1878), numerosos poemas de autores extranjeros, y cursos y manuales de Italiano (1883), inglés (1884) y francés (1884). Pero además —y aquí reside su originalidad - Obeso establece su autoridad cultural en un gesto autoparódico: esgrime 
el habla de su tierra como legítima materia de la literatura nacional. Es en esencia como el "Boga chaclatán" (18-20) que habla "ocho iriomas" y por virtud de su magia puede burlar la autoridad, estar aquí y allá.

En la "Dedicatoria" de Cantos, Obeso prometía una colección completa "de este mismo jénero, con variantes notables en la forma i la idea" (4) que se perdió o nunca existió. La obra posterior es por muchos motivos el itinerario del fracaso del este propósito. Deja atrás sus "experimentos" tras la fría recepción a ellos prodigada ${ }^{15}$ y pareciera retomar una línea romántica (Lecturas para ti 1878; Lucha de la vida 1882), hasta terminar en sus dos últimos años (1882-1883), y de manera elocuente, escribiendo gramáticas de lenguas extranjeras.

Uno de los síntomas de ese fracaso es el blanqueamiento textual en la obra, lo cual ocurre en el lenguaje, que se torna acartonado y ampuloso, y respecto a la identidad étnica. La figura de la mujer en Cantos, por ejemplo, es - salvo por el caso del poema "Lucha i conquijta" $(32,33)$ - campesina y racialmente definida como morena, negra o parda:

\section{Mi paisanas son pacdita; \\ La re uté son colorá; \\ Ma re aquellaj en er pecho}

Jierve er má (“Arió”31).

En la obra posterior, en cambio, es angelical y blanca. Jackson afirma que Obeso estaba aún expresando su orgullo de raza y su identidad negra (Black Writers 60) y para probarlo cita un fragmento del Lecturas para ti, memorial misógino y lloroso con el que el poeta pretendía lograr la simpatía y amor de una señorita bien de la sociedad bogotana:

Mi haraposo vestido me alejó de las gentes. La terrible miseria en que he vivido, mi triste desamparo, la cutis de mi raza y de mi clima, rico en tantas grandezas, trajeron sobre mi tremendos desengaños (Obeso 1950, 54).

Sin embargo el tono general tanto de Lecturas para ti como de Lucha de la vida es el de una evidente fascinación por la blancura de la amada.

Por otro lado, es importante anotar que en esas obras, además del regreso al Romanticismo imitativo y el blanqueamiento textual, persisten intensificados ciertos motivos de Cantos, a saber:

1. La denuncia política contra el elitismo

Lucha de la vida hace una crítica del teatro de cinismo, corrupción y oportunismo que veía en la sociedad y Lecturas para ti, más allá de su estrategia cortesana, denuncia apasionadamente el elitismo y los privilegios económicos y de cuna:

Los hijos de los nobles de sangre son momias en el mundo. [...] La nobleza española es hoy un fósil; la aristocracia nuestra un espantajo, una triste rapsodia [...] En la créme de la créme no hay sino cieno, raquitismo, patrañas [...] Son muy pocos los ricos. [...] se mantienen del

\footnotetext{
15 "La aparición en la sociedad bogotana del siglo XIX de un libro de poesía [de] un negro costeño [...] no causó mucha sensación editorial a pesar del uso exclusivo del lenguaje" (Prescott 64-65).
} 
fraude y del engaño [...] La mujer es un mueble para ellos y hasta finca raíz en la que especulan [...] Su conato es ser blancos y bonitos [...] A mí me honra el ser negro y mi fealdad me encanta (Obeso 1950, 51).

Es por lo menos rara esta declaración de principios contra la estratificación social aristocrática y económica en el contexto del Romanticismo colombiano, y su expresión es más amarga en comparación con el mismo ideario presente en Cantos:

Trite vira é la der probe,

Cuando er rico goza en pá,

Er probe en er monte sura

O en la ma ("Canción der pejcaro" 38).

2. La decepción del poeta frente al proyecto nacional, deviene en una utopía extraña en La lucha de la vida:

Pobre Patria! De esta suerte,

Qué porvenir te espera?

$[\ldots]$

Los vicios del Viejo Mundo,

Mal imitados, te cercan;

Las utopías mas extrañas

Hay quien en leyes convierta (Cantos 101).

[...] La gloria es humo,

La patria una ilusión (205).

Ya Cantos expresaba una tensión irresuelta entre un exaltado patriotismo y cierto desencanto; un sentimiento que Prescott notó como una "distancia de las agitaciones y acontecimientos políticos y sociales del país" (87) y una negativa a ser "carne de cañón para adelantar los intereses ajenos" (89).

Aunque había sido militar, Obeso "no se apasionaba en la lucha diaria de los partidos y se reía de los afanes de sus amigos que estaban mezclados en la contienda" (Añez 19). Empezaba a reconocer una traición que ya sentían los grupos étnico-culturales que habían peleado contra España ilusionados por la manumisión de esclavos prometida por Bolívar (Prescott 56) y luego en las guerras que siguieron a las constituciones liberales defendiendo las "conquistas" teóricas del liberalismo. ${ }^{16}$ El cuadro de costumbres "El boga" (1841) de Rufino José Cuervo, sobre las críticas de un francés por la barbarie de las tierras recorridas en una embarcación por el río Magdalena, refiere las quejas de un boga en este sentido:

16. También pelearon ante la amenaza en el discurso de algunos conservadores del restablecimiento de la esclavitud. Ese miedo lo usaron los liberales para sumar a sus tropas a la negritud (Taussig 6466). Un caso curioso y elocuente es que a los soldados en los textos de la época no se los identifica simplemente con el rango, sino que se les agrega el adjetivo racial (Tirado-Mejía 47) 
"el boga trabaja desde el amanecer hasta el anochecer, aguanta calor y mosquitos, come mal; por eso nunca llega a viejo [...] Catorce pesos recibimos, la mitad en mala moneda y la otra mitad en ropa podrida" [...] Después supe que el boga de la conversación había sido soldado y hecho las campañas de Venezuela y Perú, y que obtenida su licencia había vuelto al oficio de boga en el que se había criado. Un día se quejaba él mismo de la ingratitud de la patria con los bogas (516).

Esa protesta recuerda los versos del momposino a propósito de la futilidad del valor y el sacrificio por la patria:

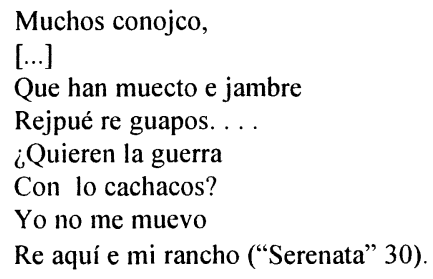

Cantos es apenas posterior a la guerra civil de 1876 en la que Obeso recibió el grado de sargento mayor y después de la cual quedó "en la misma miseria que antes, sin ninguna posibilidad de salir de ella" (Prescott 63). Sabemos que algunos poemas como "Canción der boga ausente" anteceden la experiencia bélica, mientras que otros dejan ver que fueron escritos después. En éstos últimos se lee la traición sufrida y el deseo de sustraerse al "proyecto nacional" que le dio la espalda a la negritud.

$\mathrm{Ni}$ las letras ni la sangre pagaban el precio de la ciudadanía plena. De allí el escepticismo del poema "Serenata", en el que el poeta no acepta la causa como propia sino como cosa de cachacos (bogotanos) y, mencionando sus días de soldado, invita a los que quieren la guerra a buscar otra "escalera" para treparse en lo alto de posiciones políticas:

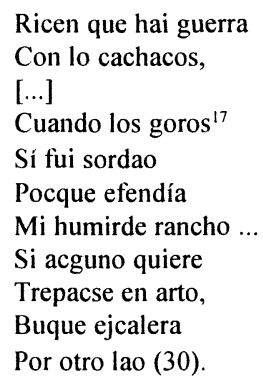

Con todo y la ley de manumisión y el "abrazo fraterno" y no obstante que los negros, de acuerdo a la retórica oficial, se pusieron "el gorro frigio de la libertad", su ciudadanía fue

${ }^{17}$ Godos se les llamaba a los conservadores. 
de tercera. Las guerras no cambiaron sustancialmente su situación de marginación social, y de pobreza. Excluidos del poder económico, político y del mundo cultural europeizado de la república, grandes grupos establecieron comunidades de economía de subsistencia en zonas baldías donde el poder del criollo no llegaba. También, en algunas ciudades poblaciones negras crecieron pauperizadas y explotadas por la burguesía citadina y más tarde por la industria que hoy está terminando de devorar el sistema frágil de estas comunidades independientes y de economía precapitalista (Taussig).

\section{ReCUPERAR LA PALABra}

La narración de la nación del siglo XIX está redactada en un discurso que de dientes para afuera dice abrazar a todos, sin hacer explícitas las intenciones homogenizadoras $\mathrm{y} /$ o excluyentes del abrazo. En el múltiple y conflictivo proceso de imaginarse la nación, no es pertinente presentar a Obeso como síntoma de la amplitud del proyecto decimonónico, pero tampoco hacer de su obra una hipérbole de resistencia desde la letra.

En un interesante, aunque en algunos aspectos discutible, ${ }^{18}$ ensayo sobre la relación poder-palabra en el siglo XIX en Colombia, que relee el trabajo de Deas, Erna von der Walde, decía:

Siempre está la sospecha de que perdimos la palabra cuando ésta se amuralló tras las gramáticas y los diccionarios [...] La utopía consiste en intentar desandar ese camino, recuperarla, sacarla de ese lugar. Y hacerlo con palabras (82).

Creo que las palabras son insuficientes para desandar los pasos, y que recuperar la palabra (al menos la que nos sirve para escribir desde la Universidad de los Andes o la de Pittsburgh) pudiera no ser una utopía deseable, en el sentido de concebirla como un lugar paradisíaco, un edén perdido en el camino. La bondad de la letra es aparente y el pasado, merced a la vigencia de su conflicto y su carga amenazadora, no es un lugar de concordia.

En Cantos hay una amenaza no sólo a los discursos edulcorados de armonía racial sino al orden de la "Atenas" donde hoy la gramática es remplazada por la teoría homogenizadora neoliberal (otra utopía de la ciudad letrada) que se diseña desde la Universidad de los Ande ${ }^{19}$ o la Javeriana. Hoy no se decide la cosa pública en el "Altozano" de la catedral como en tiempos de Obeso, sino en otros lugares generadores de marginalidad, como las universidades.

\footnotetext{
${ }^{18}$ La insinuación de que la ciudad letrada asesinó a Rafael Uribe es equivocada. En primer lugar, él era miembro preclaro de la cuidad letrada y no su opositor como parece que lo ve von der Walde (80), y en segundo lugar, "Caro y sus seguidores" no pueden ser acusados sin ofrecer una discusión histórica detallada del asunto.

${ }^{19}$ Ella afirma su lugar de enunciación como una ciudad amurallada (la letrada). Es entonces oportuno preguntarse a quiénes protege esa muralla que es física y no sólo metafórica en el caso de la Universidad de los Andes, y si la exclusión que implica, y los procedimientos de diferenciación que conlleva, no son parte del diseño de un mundo de signos "armónico", como esa gramática en la que "perdimos la palabra".
} 
Es difícil liberar desde la letra la amenaza contenida en la poesía-ventana de Obeso, para que irrumpa e ilumine el presente y lo llene del currulao que no logró detener la modernización como temía Samper, para que lo inunde con el bullicio y el "ham ham" de los bogas que los vapores devoraron, y con el olor del río vertebral que el progreso doblegó. $\mathrm{Y}$ es que la amenaza de Cantos nació atrapada por la letra.

\section{El ENTIERRO LETRADO}

Sin perder de vista que la "subversión" literaria hace visibles / legibles las narrativas marginales con la complicidad de la autoridad oficial de la cultura y le sirve al status quo para reforzar la patria gramatical como las faltas de ortografía merecen atención para confirmar la regla, podemos repensar esa anécdota del momento final del poeta de manos de las coordenadas de lectura propuestas. Obeso le apuntó al blanco y corresponde a la crítica, hoy un poco desganada, juzgar entre otras cosas, la puntería del poeta. Porque la obra encañonaba no a sí misma en un gesto romántico decadente, sino al anillo escriturario de una ciudad con pretensiones grecolatinas.

A enterrar al poeta acudieron insignes miembros de la ciudad letrada como Salvador Camacho Roldán y Miguel Antonio Caro. Enterraban también su obra. Su exhumación moderna ${ }^{20}$ motiva una lectura que empieza a destrabar el momento en que el poeta le apuntó al blanco y le dio al blanco, recordándole a Atenas que tenía a Africa consigo.

Ese momento, fugaz como una iluminación, relampaguea para iluminar en su justo valor tratados ortográficos rimados, disquisiciones sobre el "que galicado", "gorros frigios" de fraternidades mentirosas, ensayos académicos como éste y por supuesto el hoy desde el cual Obeso, regresa de la polis andina a su tierra, sin otra cosa que un tiro en el vientre y las promesas rotas de la república:

\footnotetext{
Ya me voi re aquí eta tierra

A mi nativa morá;

Er corazón é ma grande

Junto ar má! (“Arió” 32).
}

\footnotetext{
${ }^{20}$ Además del trabajo de Prescott, vale la pena resaltar que Artel establece en Obeso su genealogía literaria y que el músico colombiano Antonio María Valencia (1902-1952), en un rescate vanguardista del trabajo del momposino, con base en "Canción der boga ausente", compuso una breve obra coral profana para cuarteto vocal, coro mixto a capella y maracas y cuyo subtítulo es Polifonia y polirritmia vocal (1937), (Triana y Antorveza 394-95).
} 


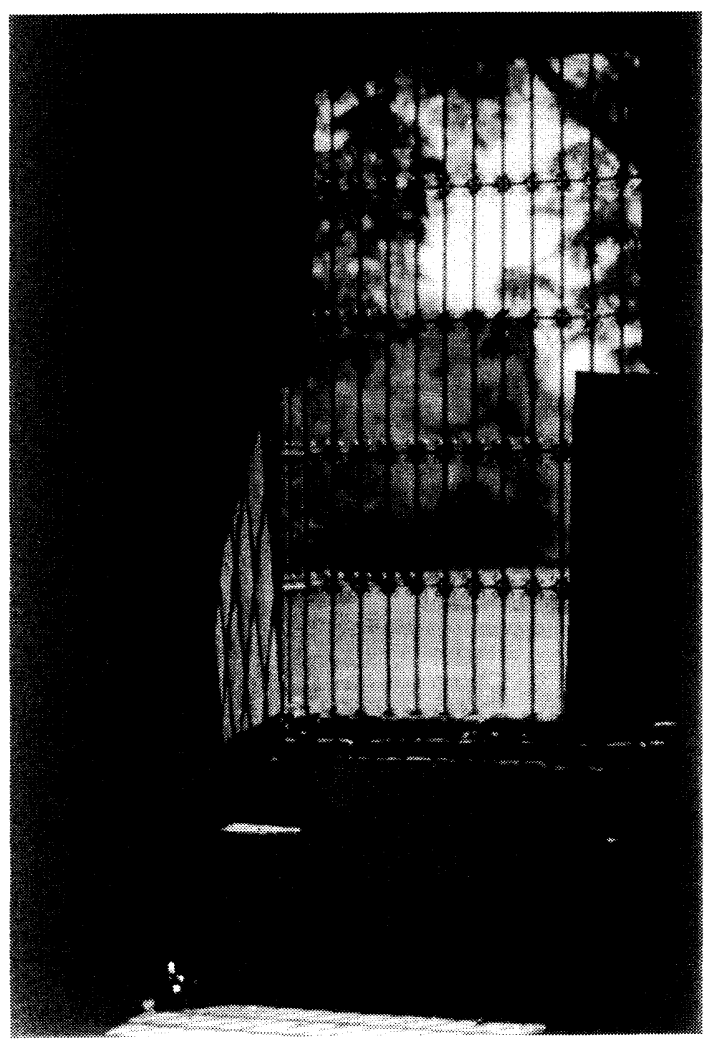

A RIÓ.

Ya me voi re aquí eta tierra A mi nativa morá;

No vive er peje richoso Fuera ér má! ....

Siempre er sitio onde se nace Tiene ciecta noverá; .... Yo no jallo la alegría Lejó ér má.

La panela re ete pueblo Ej esauta a la re allá; Pero a aquella la meccocha L'aire ér má.

Mi paisanas son pacdita; La re uté son colorá; Ma re aquellaj en er pecho Jierve er má.

Ete só vive anubláo Re una etecna ejcurirá; Aquér só bujca er epejo Re la má.

Aquí er probe campecino Vive en trite solerá, Mui rijtante der que vive Junto ar má.

Mompox, Andrés Biermann, 1998.

Re eta tierra en lo playones

No se topa onde sejteá;

Hai un bojque mui tupío Cecca ar má.

Aquí er ojo se fatiga

Re un ajperto contemplá; ....

¡Cuánta e varia la hecmosura

Re la má!....

Ya me voi re aquí eta tierra A mi nativá morá;

Er corazon e ma grande

Junto ar má!

Obeso, Candelario. Cantos populares de mi tierra. Bogotá: Imprenta de Borda, 1877 (32). 


\section{Bibliografia}

Anderson, Benedict. Imagined Communities: Reflections on the Origin and Spread of Nationalism. New York: Verso, 1991.

Añez, Julio. "Candelario Obeso". Papel periódico ilustrado 74, (septiembre 1, 1884): 17 19.

Benjamin, Walter. Illuminations. New York: Schocken Books, 1988.

Beverley, John. Against Literature. Mineapolis: University of Minnesota, 1993.

Bourdieu, Pierre. Reproduction in Education, Society, and Culture. London: Sage, 1990.

Cané, Miguel. "Notas de viaje sobre Venezuela y Colombia 1882". Bogotá en los viajeros extranjeros del siglo XIX. Bogotá: Villegas editores, (1990): 176-198.

Carnegie-Williams, Rosa. Un año en los Andes, o, aventuras de una lady en Bogotá. Bogotá: Tercer Mundo, 1990.

Cordovez-Moure, Jose María. Reminiscencias de Santafé de Bogotá. Madrid: Aguilar, 1957.

Cuervo, Rufino-José. "El boga". Crónica Grande del río de la Magdalena 1. Aníbal Noguera, ed. Bogotá: Sol y luna, 1980. 515-517.

Diccionario de construcción y régimen de la lengua castellana. Tomos 1-2. Paris: A. Roger y F. Chernoviz, 1886-93.

Deas, Malcom. Del poder y la gramática y otros ensayos sobre historia, politica yliteratura colombianas. Bogotá: Tercer mundo, 1993.

Fals-Borda, Orlando. Mompox y Loba. Bogotá: Valencia, 1979.

Gates, Henry Luis, Jr. "Writing 'race' and the Diference It Makes". Race, Writing and Difference. Chicago, University of Chicago Press, 1986. 1-20.

González-Stephan, Beatriz. "Las disciplinas escriturarias de la patria: constituciones, gramáticas y manuales". Estudios: Revista de investigaciones literarias 5(1995): 19 46.

Guillen, Nicolás. "Candelario Obeso". Prosas de prisa (La Habana, 1962): 302-306.

Hall, Stuart. Race: The Floating Signifier. Dir. Sut Jhally. The mediaEducation Foundation, 1997.

Hettner, Alfred. "Viaje por los Andes Colombianos 1882-1884". Bogotá en los viajeros extranjeros del siglo XIX. Bogotá: Villegas editores, 1990. 201-258.

Humboldt, Alejandro. "Diario de viaje por el Magdalena". Crónica Grande del río de la Magdalena 1. Aníbal Noguera, ed. Bogotá, Sol y luna, 1980. 145-160.

Jackson, Richard. Black Writers in Latin America. Alburquerque: University of New Mexico Press, 1979.

“Afro-Hispanic Literature: 'Recent Trends in Criticism"'. Afro-Hispanic Review $7 /$ 1, 2, 3 (1988): 32-35.

Jaramillo Uribe, Jaime. Manual de historia de Colombia. Bogotá: Procultura: Instituto Colombiano de Cultura, 1984.

Jaramillo-Zuluaga, J. Eduardo. "Artes de la lectura en la ciudad del Águila Negra: la lectura en voz alta y recitación en Santa Fé de Bogotá a fines del siglo XIX". Revista Iberoamericana LXIV/184-185 (1998): 471-483. 
Jiménez, Blas. "El escritor afro-hispano y el proceso creativo. Afro-Hispanic Review (Spring 1995): 3-9.

Kastos, Emiro (Juan de Dios Restrepo). "Bogas verdaderos y bogas apócrifos". Crónica Grande del río de la Magdalena 1. Aníbal Noguera, ed. Bogotá: Sol y luna, 1980. $519,520$.

Lagos, Ramiro. "La poesía ebanita y su precursor Candelario Obeso". Boletín cultural y bibliográfico 20/1 (Bogotá, 1983): 217-227.

Madiedo, Manuel. "El boga del Magdalena”. Crónica Grande del río de la Magdalena 1. Aníbal Noguera, ed. Bogotá: Sol y luna, 1980. 511-513.

Mansour, Mónica. "El negro en la poesía romántica y costumbrista". La poesía negrista. Méjico: Era, 1973. 76-106.

Marroquín, José-Manuel. Tratado de ortología y ortografia de la lengua castellana. Bogotá: Imprenta de Gaitán, 1869.

Múnera, Alfonso. El fracaso de la nación: región, clase y raza en el Caribe colombiano (1717-1821). Bogotá: Banco de la República, Ancora Editores, 1998.

Obeso, Candelario. Cantos populares de mi tierra. Bogotá: Imprenta de Borda, 1877; Bogotá: Ministerio de Educación, 1950.

Peñas, David. Los bogas de Mompox: historia del zambaje. Bogotá: Tercer mundo, 1988.

Prescott, Laurence. Candelario Obeso y la iniciación de la poesía negra en Colombia. Bogotá: Instituto Caro y Cuervo, 1985.

"'Negro nací:' Authorship and Voice in Verses Attributed to Candelario Obeso". Afro-Hispanic Review 12/1 (1993): 3-15.

Rama, Ángel. La ciudad letrada. Hanover: Ediciones del Norte, 1984.

Ramos, Julio. "El don de la lengua". Paradojas de la letra. Caracas, Venezuela: Ediciones eXcultura, 1996. 3-21.

Renan, Ernest. "What is a nation?" Nation and narration. Homi Bhabha, ed. London; New York: Routledge, 1990.

Saffray, Charles. "Viaje a Nueva Granada 1869". Bogotá en los viajeros extranjeros del siglo XIX. Bogotá: Villegas editores, 1990. 156-173.

Samper, Jose María. "Un viaje completo". Crónica Grande del río de la Magdalena 2. Aníbal Noguera, ed. Bogota: Sol y luna, 1980. 87-100.

Smith-Córdoba, Amir. Vidayobra de Candelario Obeso. Bogotá: Centro para la investigación de la cultura negra, 1984.

Socarrás, José Francisco. "En el centenario de Candelario Obeso". Boletín de la Academia colombiana 150 (octubre, noviembre y diciembre de 1985): 245-261.

Taussig, Michael. The Devil and Commodity Fetishism in South America. Chapel Hill: University of North Carolina Press, 1980.

Tirado-Mejía, Alvaro. Aspectos sociales de las guerras civiles en Colombia. Bogotá: Instituto Colombiano de Cultura, 1976.

Triana y Antorveza, Humberto. Léxico documentado para la historia del negro en América (siglos XV-XIX). Bogotá: Instituto Caro y Cuervo, 1997.

Von der Walde, Erna. "Limpia, fija y da esplendor: el letrado y la letra en Colombia a fines del siglo XIX". Revista Iberoamericana LXIII/178-179 (1997): 71-83. 
Wheat, Valerie. "Nineteenth Century Black Dialect Poetry and Racial Pride: Candelario Obeso's Cantos populares de mi tierra and Paul Laurence Dunbar's Lyrics of Lowly Life". Afro-Hispanic-Review 15/2 (1996): 26-36. 